\title{
An Approach for Sustainable material selection using Life Cycle Assessment
}

\author{
Mohamed Magdy, Fatma O. Alamoudy, Walaa S.E. Ismaeel,
}

Architectural Engineering Department, The British University in Egypt, El-Sherouk City, Egypt

\begin{abstract}
:
The construction industry is one of the biggest exploiters of both renewable and non-renewable resources in the world. Therefore, it was unavoidable that concerns will be raised with respect to the environmental effect of this industry. As the procedure of building consume many material through its life cycle, the determination and utilization of sustainable building material were assessed due to their important role in the planning and construction of a green building. This study is set up to show an approach for sustainable building material selection and their effects on nature. It likewise talk about the life cycle assessment as a methodological role and system and its limitation for the examination of sustainable building material. This will be conducted through a comparative analysis of the most common material used in construction industry in Egypt; which are concrete and steel. The analysis investigates the amount of energy consumed and greenhouse gases emitted through out the material life cycle. This study shows that using steel in construction can be less damaging to the environment as well as saving energy used in building life cycle.
\end{abstract} Keywords: Concrete; Steel; Life Cycle Assessment; Sustainable materials. 


\section{Nomenclature}

\begin{tabular}{l|l|} 
EC & Embodied Carbon \\
EE & Embodied Energy \\
GHG & Greenhouse Gases \\
LCA & Life Cycle Assessment \\
SBM & Abiotic Resource Depletion Potential \\
ADP Elements & Acidification potential \\
AP & Eutrophication potential \\
EP & $\begin{array}{l}\text { Formation potential of tropospheric ozone } \\
\text { photochemical oxidants }\end{array}$ \\
POCP & Global Warming Potential \\
GWP &
\end{tabular}




\section{INTRODUCTION}

The construction industry is known to be a nonenvironmental-friendly discipline. This is found to be due to its significant impact on the resources and energy consumption. Moreover, the construction industry has a significant role in the emission of Greenhouse gases because of fossil products burning. Whereas, it was found that it takes $40 \%$ of environmental materials, expends $40 \%$ of the energy consumed, $15 \%$ of the planet's water resources, generates $25 \%$ of all wastes and emits 40-50\% of Green House Gases (Ramesh et al., 2010; Mokhlesian and Holmén, 2012). According to the previous, it can be assumed that the problem is all about material selection and their specifications.

This study aims at surveying the effects of two commonly used building materials in Egypt on the environment and how this environmental impact affects material selection. The research will analyze construction materials (concrete and steel) determining the amount of GHG emitted during the materials lifecycle as well as the amount of energy consumed.

\section{SUSTAINABLE BUILDING MATERIAL(SBM)}

In the construction industry, steel and concrete are found to be the most commonly used traditional materials. Both materials are known to be high embodied energy that have severe impact on the overall performance of buildings through its lifecycle. According to John (2015) the definition of embodied energy (EE) is the energy that is consumed and used in the manufacturing process. Embodied carbon (EC) is the carbon that is emitted through the manufacturing process.

According to Franzoni (2011), the selection of building materials plays a major role in attaining sustainable development. This area is largely obscure because of the large number of factors and varieties where various studies discuss issues with materials selection. In any case, the the development process, operation and maintenance to the emanation of hurtful majority of these examinations have agreed upon and sufficiently set up the definition of SBM. Even today there is no all-around acknowledged definition of SBM which makes it very difficult to the develop standards and rules that make selection of building materials consistent with SBM objectives (Franzoni, 2011; Saghafi and Teshnizi, 2011). However, SBM can be considered as materials characteristic where it offer the user advantages in low maintenance terms, energy efficiency, increasing the well-being and comfort of the occupants, growing productivity while being cleaner to the community (Franzoni's, 2011). A misconception about SBM is that all natural materials are sustainable. However, this is not true. For example, natural materials, such as radon, turpentine and asbestos, may not be SBM materials as they are detrimental to the natural environment. Hence, materials should be chosen according to their impact on the environment not their source of production. (Spiegel and Meadows, 1999; Franzoni, 2011).

Moreover, sources of SBM are required to be recyclable that cannot be renewed. Other characteristics of these materials is that they should be maintained during their life cycle and need less energy to be used in the assembly process. Furthermore, these materials should not emit pollution or different outflows that affect people wellbeing through the building life cycle (Cagiao J , Gomez, 2010).

\section{ECOLOGICAL SUSTAINABLE DEVELOPMENT (ESD)}

From a development perspective, Ecological sustainable development (ESD) can be explained as utilized resources are competitively determined to fulfil the necessities and requirements of modern day and future generations whereas preventing the unfavorable effects on the surrounding environment. Moreover, reducing the negative material impact the users throughout

substances at some stage within the buildings life cycle. 
Building construction is not an ecologicalfriendly process as it has significant effects on the natural environment due to the GHG emission. In the United States, the construction industry contributes towards $1 / 3$ in terms of greenhouse gases emissions ( $\mathrm{Li}$ et al., 2010) Moreover, the construction industry contributes to $40-50 \%$ of greenhouse gases emission worldwide. Furthermore, construction industry contributes in the consumption of $40 \%$ of natural material, consumes $40 \%$ of the energy sources, $15 \%$ of water sources and responsible for the production of $25 \%$ wastes. (Ramesh et al., 2010; Mokhlesian and Holmén, 2012) This can be shown in figure 1; Showing the increasing trend of material use during the last years such as Aluminum, Gypsum, Iron, Limestone and Phosphate rock.

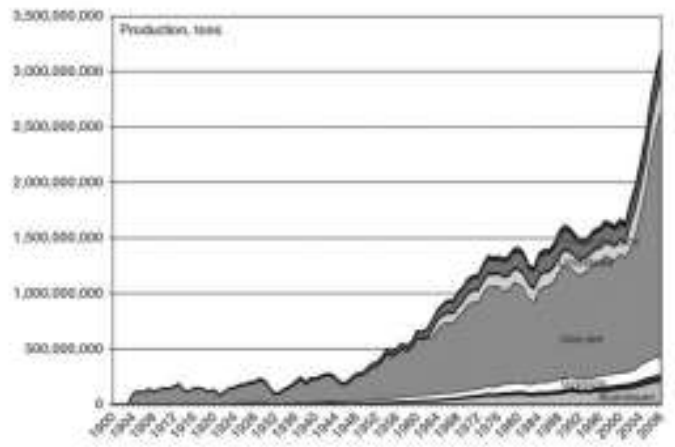

Figure 1: materials quantities used in the construction from 1900 to 2008 (Ramesh et al, 2010)

\section{SELECTION CRITERIA FOR SUSTAINABLE BUILDING MATERIAL (SBM)}

A sustainable construction process should be considered along the entire life cycle of a building; selecting, restoring, replacing and transforming of building materials should be characterized with the following criteria:

\section{* Resource efficiency}

Resources efficiency is all about the use of the limited resources while not confining monetary development on the society. Hence, the usage of resources should be dealt cautiously and mindfully, specifically as they are recognized to affect the user experience

(Halliday, 2008).

\section{* Energy performance}

The intensity of embodied energy of building materials shifts from region to region, reckoning on the energy sources, use and therefore the accumulation method. The embodied energy of building materials include initial embodied energy. Embodied energy identifies with the building materials used for construction, whereas continuance embodied energy is the energy that is used in the manufacture process (Bohne, 2014)

\section{* Pollutants prevention}

Sustainable construction materials need to be recyclable or reusable in that they may be correctly disposed at the end of their beneficial life (Gao et al. 2001). Incorporating sustainable material is crucial to save embodied energy and conserving natural assets where reusing is a must so that it contributes to avoiding contamination.

\section{THE STRATEGY FOR SELECTING SUSTAINABLE MATERIAL}

SBM depends on choosing materials from efficient techniques, for instance, choosing substances of an occasional embodied strength content, making use of locally provided and assets power resources, at the same time as choosing materials that make less contribution of GHG emissions to the air. As a consequence, an examination into new material introduction, manufacturing methods, reusing of building materials and using low embodied strength substances has become very critical.

Thormark,(2012) studied the natural reused building materials effects for single-family 
houses and presumes that the ecological effects are fifty-five percent of the outcomes that are induced if all the materials have been sourced as new.

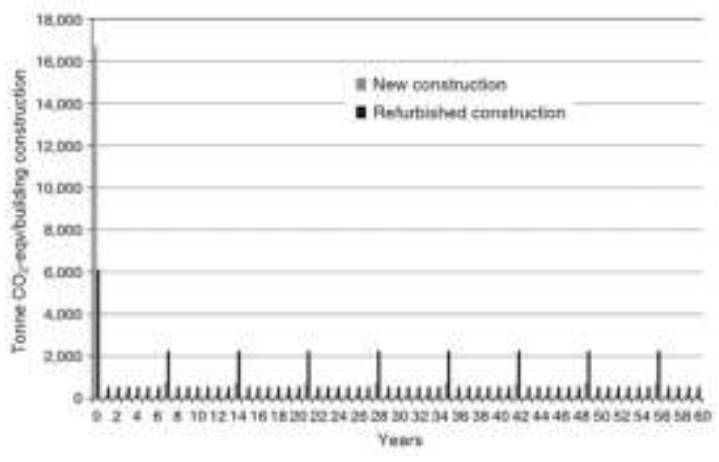

Figure 2: the difference between new construction and refurbished construction in $\mathrm{CO}_{2}$ emissions. (Saghafi and Teshnizi, 2011)

\section{SUSTAINABLE BUILDING MATERIAL AND ECOLOGICAL BUILDING DEVELOPMENT}

An enormous concern that exemplifies both ecological management and safety control is known as an ecologically sustainable improvement. The ecologically sustainable development idea is fundamental in building up a sustainable improvement goal. In buildings, it includes the productive resources distribution, least energy usage, and low embodied power in constructing substances, recycle and reusing, and totally distinct systems to accomplish prevailing and powerful short and semi-everlasting usage of normal sources. The improvement within the natural structure's performance will certainly inspire ecological responsibility (Thormark, 2000).

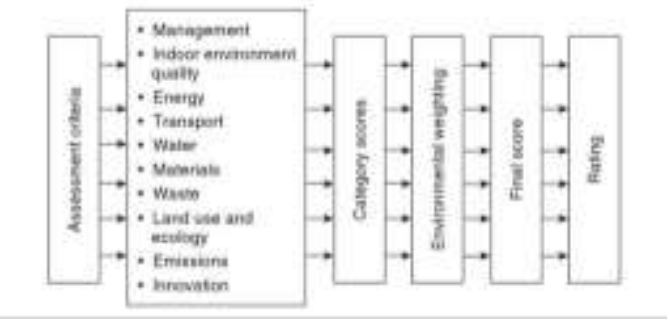

Figure 3: the criteria shows the assessment for choosing sustainable materials (Teshnizi, 2011)

\section{LIFE CYCLE ASSESSMENT}

Sustainable building construction includes natural materials utilization as well as manufactured materials that require huge amount of consumed energy. Moreover, sustainable material stresses on its impact on user health, while not having nephrotoxic specification to limit pollution (Halliday, 2008). Moreover, another equally vital objective is the decrease of waste and losses throughout the material manufacture, the development process and the duration of the lifecycle of the finished structure. Materials reuse throughout the demolishing phase of a structure ought to likewise be considered. The reusing procedure needs to be rigorously organized to guarantee that these materials will maintained to reach their distinctive quality.

\subsection{LCA HISTORY}

The concept of LCA was created in Europe and the USA during 1960s and mid-seventies. In the late Eighties and middle Nineties LCA got extra attention as a response to the distended natural awareness and concern for electricity usage. Likewise, it empowers the measuring and identification of materials used, vitality and waste discharged to nature over the entire building cycle (Klopffer, 2006). 


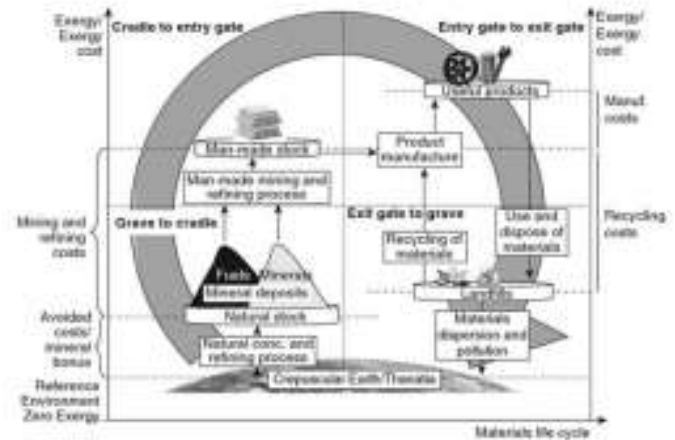

Figure 5: The life cycle of the raw material 'cradle to grave'. (Klopffer, 2006)

In 1997 International Organization for Standardization (ISO) disbursed the primary ISO 14040 series to rate the standards and standards on the LCA method (Perez-Garcia et al., 2005). In 2006, the ISO 14040 association became modified. The ISO 14040 administers the requirements and structures, while ISO 14044 includes the necessities and guidelines for leading LCA research (ISO, 2006a, 2006b). The ISO technique contained in these standards is central to the standardization and hence the discoveries generalizability regarding all LCA studies and life cycle inventory (LCI) studies and researches.

\subsection{The use of LCA}

LCA has been normally used in the U.S. and Europe, first of all, for comparison material performance. Its tool has been extended to encompass materials products, whole building LCA and strategic designing (Kohler and Moffatt, 2003; Scheuer et al., 2003). LCA allows an evaluation of outcomes that are made and dispensed across different methods for the duration of the life cycle. (Puettmann and Wilson, 2005). Ortiz et al. (2009) specified that LCA may be an essential method for evaluating consequences. LCA has been used within the building industry since 1990 .

\subsection{The tools of LCA}

There is an unbelievable variety of tools for ecological evaluation of the engineered condition, this includes, indoor air satisfactory to all or any constructing evaluation and electricity labelling, and later to a city-scale engineered evaluation of the environment like Gabi, BEES, Sima-pro and open LCA.

Cole (1998) recommends that the LCA approach is used as the main valid assessment method. The LCA approach is intend to minimize the natural burden of materials as it put into effect a tradeoff examination to perform a decrease in ecological impacts.

\subsection{LCA limitations}

LCA may be a complicated process as it evaluates and compares at material product inflows and emanations outflows related to building material at

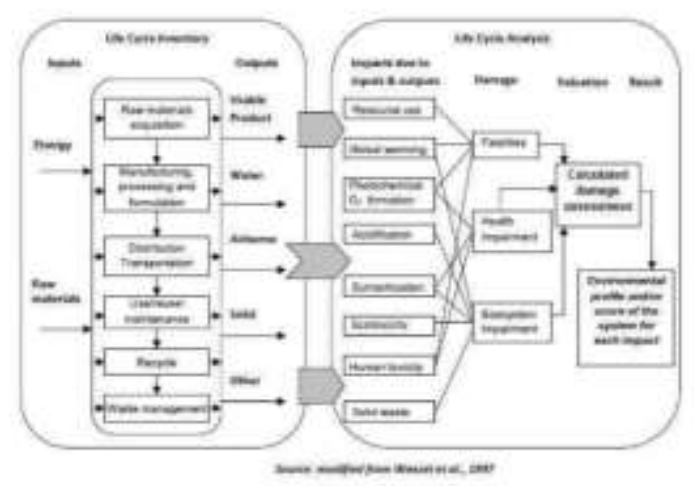

numerous scales and in diverse contexts.

Figure 5: Shows the inputs and outputs of life cycle inventory, modified from (wenzel, 1997)

\section{LCA and Sustainable building materials}

Material level at its core, process-based LCA is defined at the material level and submitted for inclusion in various LCI databases. Product-level LCA data is growing in the market. LCA is calculated as a collection of 
materials which are assembled into a final (or intermediate) product, calculating each inputs and outputs.

The role of life cycle assessment for this level is to prescribe and streamline environmental product certification programs which represent a key component in the design for environmental approach. Three types of product environmental label exist and are defined in ISO 14020 (2000). These are;

-The eco-certification environmental labels (type 1).

- The self-declared environmental claims (type 2).

-The environmental declarations (type 3 ).

Type 2 is the most prevalent type of environmental labels in the market place but with the least connection to LCA studies, While on the other hand (Type 3 ) is the most related and trusted type to LCA studies (Berardi, 2011)

\section{Life cycle of concrete material}

One of the foremost vital and standard construction materials within the world is concrete. It's a structure material that is invariably combined with ferroconcrete to enhance its ability in tension forces and generally, it is mixed with alternative strengthened materials. Sometimes concrete is formed from water and cement or coarse mixture and generally fine aggregate. Figure 5 shows the production life cycle of concrete (Thomark, 2006).

There are six totally different categories for concrete:
1) $\mathrm{C} 8 / 10$
2) $\mathrm{C} 12 / 15$
3) $\mathrm{C} 20 / 25$
4) $\mathrm{C} 25 / 30$
5) $\mathrm{C} 30 / 37$
6) $\mathrm{C} 35 / 45$

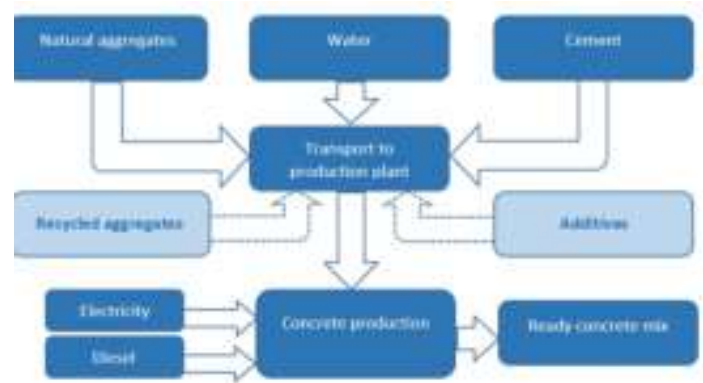

Figure 6: the Production life cycle of concrete (Thomark, 2006).

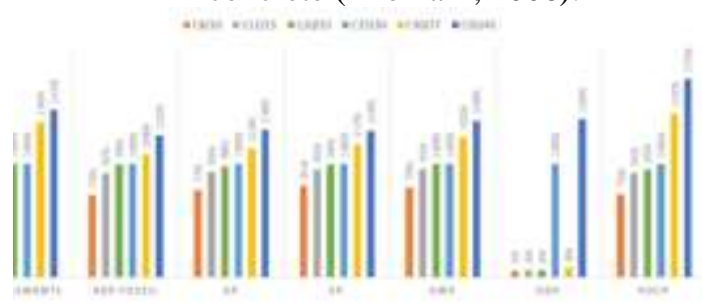

Figure 7: the environmental impact of different concrete types (Passer, 2015).

As shown in the last figure, for the all impact categories, except the Ozone Depletion Potential (ODP), whenever the classification of concrete, whenever the more potential environmental impact rise. As shown in figure 8 the primary energy for different concrete types (Passer, 2015).

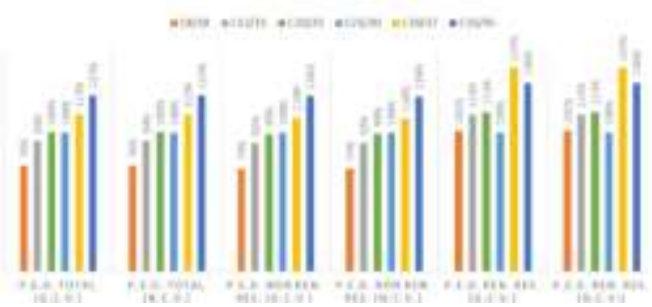

Figure 8: the primary energy for different concrete types (Passer, 2015).

The activity organized considers use and hold, repair, replacement and preservation. At the quantity of material, it makes no feel to take into account those tiers and at some point, of this technique, these modules could be discharged. 


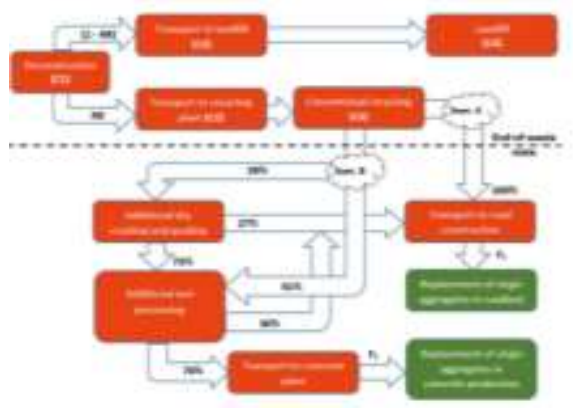

Figure 9: shows the life stages for the concrete (Regamonti, 2017).

\section{Steel Life Cycle:}

The assortment of steel elements utilized within the development of steel-framed structures is significant. Besides, steel reinforcement is employed within the ferroconcrete structures. Steel is usually factory-made by two basic courses: the electrical arc furnace (EAF) and the blast furnace (BF) route. The first distinction between these two routes is the level of scrap brought into the steel-making procedure. Which shows the life cycle of steel production. Figure 10 shows the life cycle for steel production (Ding, 2016)

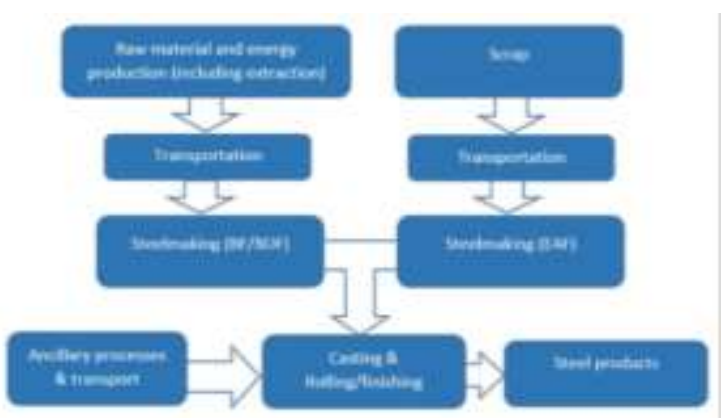

Figure 10: shows the life cycle for steel production (Ding, 2016).

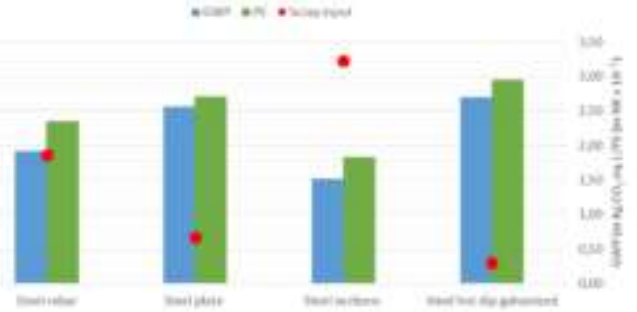

Figure 11: shows the GWP and potential energy (PE) for 1 Kilogram of a steel product with different inputs of scrap (Passer, 2015).

\section{Study Method}

In this research, a comparison between the steel structure and concrete structure in the warehouse is done to study and investigate their impact.

\subsection{Selection and Assessment criteria}

Four case studies were selected where two steel warehouse and two concrete warehouses were examined. There are two large span cases and two small span cases. These case studies were chosen based on their material of the warehouse structure and their area. In this analytical comparison, steel and concrete are perceived regarding EE and EC.

\subsection{Material structure}

According to the University of Bath, inventory of carbon \& energy (ICE) Version 2.0, This summary table shown in figure 12 and 13 includes the material that is used in the structure system in the case studies are recycled engineering steel and Concrete (16/20, 20/25). Each material has different EE and EC.

* The EE table; one kilogram from recycled engineering steel contain 13.10 MJ/KG and one kilogram from $16 / 20$ concrete contain $0.70 \mathrm{MJ} / \mathrm{KG}$, one kilogram from 20/25 concrete contain $0.74 \mathrm{MJ} / \mathrm{KG}$.

* The EC table; one kilogram from recycled engineering steel contain $0.72 \mathrm{kgCO}_{2} \mathrm{e} / \mathrm{kg}$ and one kilogram 
from $16 / 20$ concrete contain 0.100 $\mathrm{kgCO}_{2} \mathrm{e} / \mathrm{kg}$, one kilogram from 20/25 concrete contain 0.107 $\mathrm{kgCO}_{2} \mathrm{e} / \mathrm{kg}$.

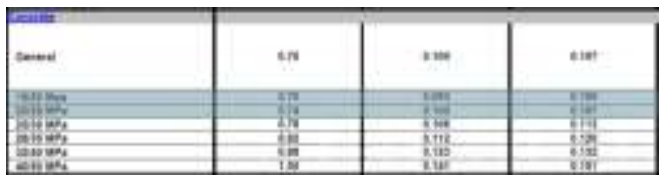

Figure 12: the embodied energy and embodied carbon for the used concrete (ICE University of Bath)

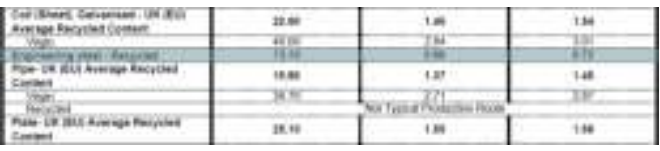

Figure 13: the embodied energy and the embodied carbon for the used steel (ICE University of Bath)

The case of concrete, the unit that is used to measure the quantity of concrete is $\mathrm{m}^{3}$ so the quantity of the concrete in the structure in Kilograms is determined, by using the density rule; density $=$ mass/volume, and the density of concrete $=2400 \mathrm{KG} / \mathrm{m}^{3}$ and we have the volume so the mass $=$ density*volume.

\subsection{Case studies background}

The First case is Steel with an area of $882 \mathrm{~m}^{2}$ (46*19). After knowing the quantity of steel in this case study which is $21050 \mathrm{KG}$.

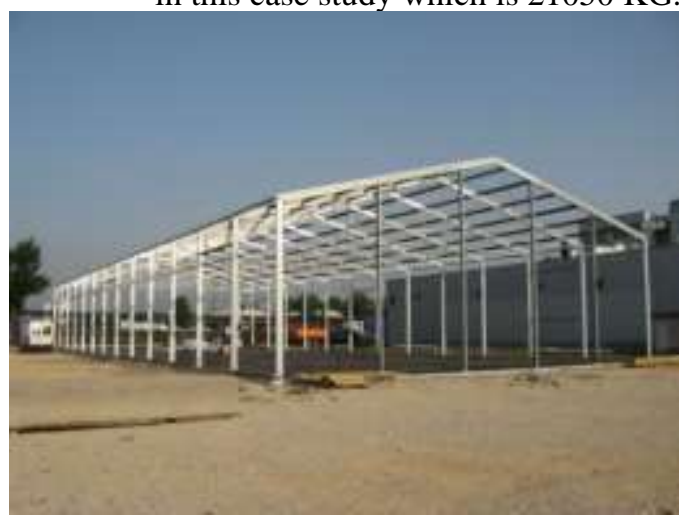

Figure 14: Shows the steel structure warehouse
The second case study is a steel case study that has $750 \mathrm{~m}^{2}$ area $\left(37.5^{* 20}\right)$. After calculating the total amount of steel that is used in the structure process which is 19112

KG.

The third case is Concrete that has $660 \mathrm{~m}^{2}$ area $\left(35^{*} 18.8\right)$. After knowing the quantity of concrete in this case study which is $307 \mathrm{~m}^{3}$, when the density of the concrete is $2400 \mathrm{~kg} / \mathrm{m}^{3}$.

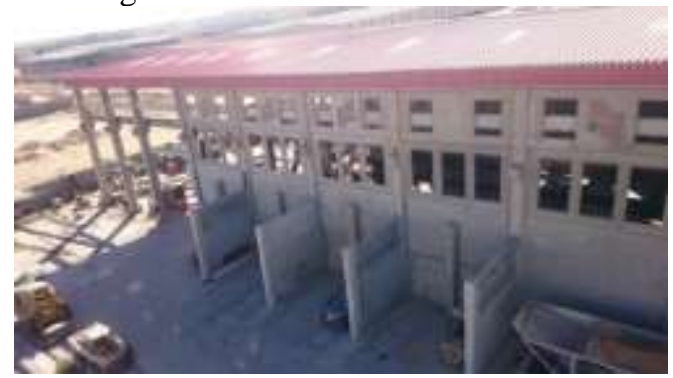

Figure 15: the concrete structure warehouse. The fourth case is Concrete that has $2000 \mathrm{~m}^{2}$ area $\left(65^{*} 30.7\right)$. After knowing the quantity of concrete in this case study which is $1449 \mathrm{~m}^{3}$, when the density of the concrete is $2400 \mathrm{~kg} / \mathrm{m}^{3}$.

\section{Data analysis (process and procedures)}

\subsection{In steel case studies:}

1) Calculating the amount of steel in kilogram that is used in the warehouse in structure system.

2) Know the EE and EC number for steel by using inventory of carbon \& energy (ICE) Version 2.0.

3) Multiply the amount of the steel that is used in a case study in kilogram to the EE amount to get the total embodied energy to the steel warehouse.

4) Multiply the amount of steel that is used in the structure system in kilogram to the EC amount to get the total embodied carbon to the steel warehouse.

5) Repeat this step to the second steel warehouse.

\subsection{In concrete case studies:}


1) Calculating the amount of concrete in the case study in $\mathrm{m}^{3}$.

2) Transfer this unit to KG by using the Density rule (Density=mass/volume).

3) Know the EE and EC number for concrete by using inventory of carbon \& energy (ICE) Version 2.0.

4) Multiply the amount of concrete that is used in the structure system in kilogram to the EE amount to get the total embodied energy to the concrete warehouse.

5) Multiply the amount of concrete that is used in the structure system in kilogram to the EC amount to get the total embodied carbon to the concrete warehouse.

6) Repeat this step to the second steel warehouse.

7) Calculating the case studies total area and then divided the total embodied energy and the total embodied carbon for each case study by the total area to know how much embodied energy and embodied carbon was consumed in every kilogram of steel and concrete.

\section{Results and Findings}

In this part, the comparison between two structure material steel and concrete in terms of their EE and EC results will be analyzed that used in the structure system in the warehouses' case studies. To see and figure which material consume energy more than the other and which one emits more carbon than the other.

\subsection{Steel Case Study (1) Analysis:}

After analyzing the first case study that has $21050 \mathrm{~kg}$ of steel in its structure system. It turned out that the one-meter square from the steel consumes $312.64 \mathrm{MJ} / \mathrm{KG}$ (embodied energy). And the one-meter square from steel emits $17.18 \mathrm{kgCO}_{2} \mathrm{e} / \mathrm{kg}$ (embodied carbon)
According to Fig. (16), the steel in the manufacturing process consumes too much energy if it is compared with the embodied carbon.

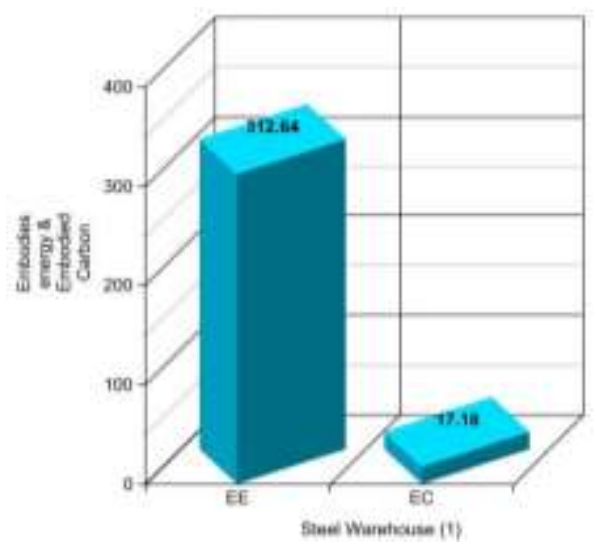

Figure 16: the embodied energy and carbon to the first steel case study.

\subsection{Steel Case Study (2) Analysis}

After analysis of the second case study that has $19112 \mathrm{~kg}$ of steel and has a $750 \mathrm{~m}^{2}$ area. It turned out that the one-meter square from the steel consumes 333.82MJ/KG (embodied energy) and the one-meter square from steel emits $18.35 \mathrm{kgCO}_{2} \mathrm{e} / \mathrm{kg}$ (embodied carbon).

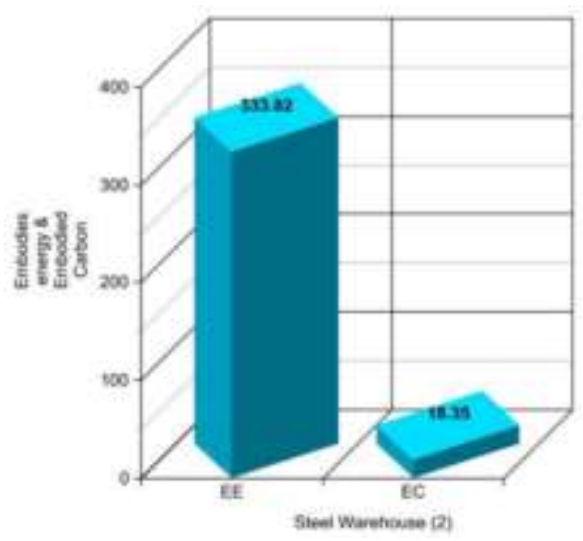

Figure 17: Shows the embodied energy and carbon to the second steel case study. According to Fig. (17), the steel in the manufacturing process consumes too much 
energy compared to the embodied carbon.

\subsection{Concrete Case Study (1) Analysis:}

After analysis of the first case study that has $307 \mathrm{~m}^{3}$ of concrete in its structural system. It turned out that the one-meter square from the concrete consumes 778.9 MJ/KG (embodied energy). And the one-meter square from concrete emit $111.272 \mathrm{kgCO}_{2} \mathrm{e} / \mathrm{kg}$ (embodied carbon)

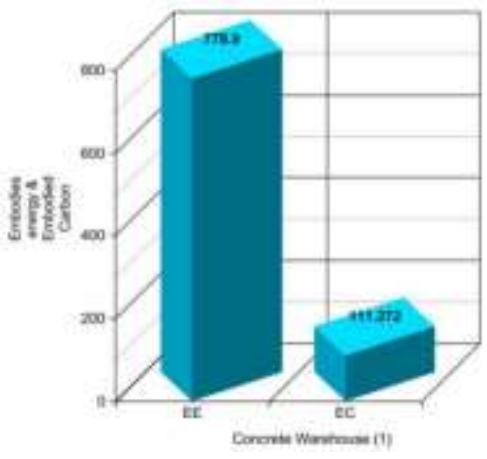

Figure 18: Shows the embodied energy and embodied carbon for concrete.

According to Fig. (18), the concrete in the manufacturing process consumes too much energy compared to the embodied carbon.

\subsection{Concrete Case Study (2) Analysis}

After analysis of the second case study that has $1449 \mathrm{~m}^{3}$ of concrete and has a $2000 \mathrm{~m}^{2}$ area. It turned out that the one-meter square from the concrete consumes $1285 \mathrm{MJ} / \mathrm{KG}$ (embodied energy) and the one-meter square from steel emits $186 \mathrm{kgCO}_{2} \mathrm{e} / \mathrm{kg}$ (embodied carbon). The results may be too much different from the other concrete case study because they use different concrete type

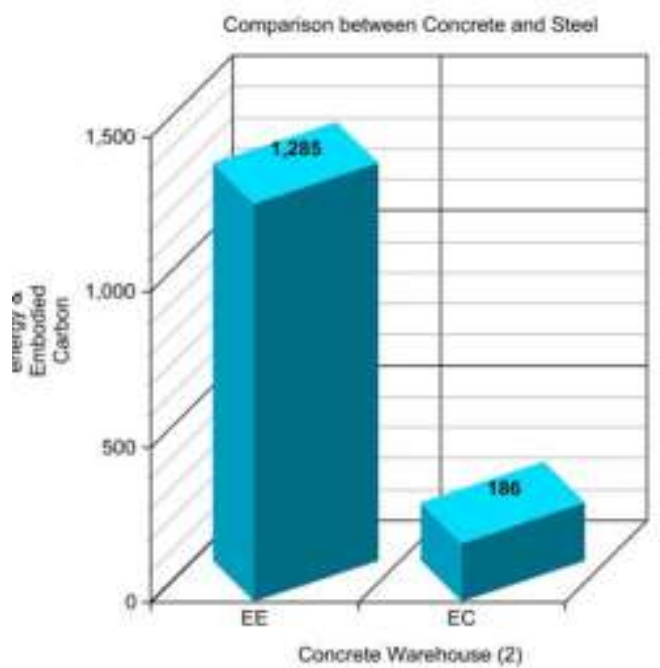

Figure 19: Shows the embodied energy and embodied carbon for concrete.

According to Fig. (19), the concrete in the manufacturing process consumes too much energy compared to the embodied carbon.

\section{Discussion}

the first two graphs (steel), the As shown in steel in the manufacturing and construction process has some benefits like it does not emit too much carbon. Each meter square from the recycled engineering steel emit $\approx 17.765$ $\mathrm{kgCO}_{2} \mathrm{e} / \mathrm{kg}$ and it is not a big amount if we compared that to any other material. And each meter square from the steel consumes energy approximately $\approx 323.23 \mathrm{MJ} / \mathrm{KG}$. While in the second two graphs (concrete), the concrete in the manufacturing and construction process consume too much energy comparing to other material like steel. The meter square of concrete consumes approximately $1031.95 \mathrm{MJ} / \mathrm{KG}$ (embodied energy). The meter square from concrete emit through the manufacturing process too much carbon that approximately equals 148.636 $\mathrm{kgCO}_{2} \mathrm{e} / \mathrm{kg}$ (embodied carbon) Therefore, it can be concluded that in terms of the embodied energy; the concrete consumes more energy than steel in the manufacturing process. 


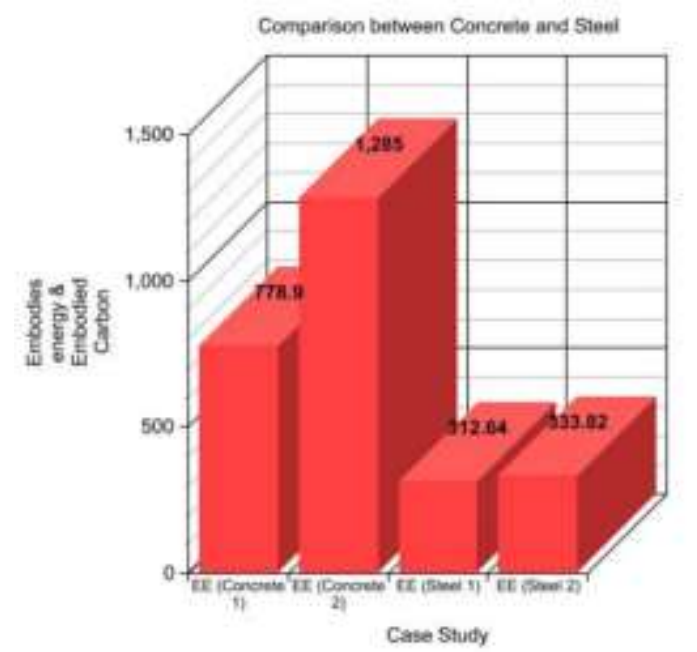

Figure 20: the difference between the steel and concrete in embodied energy.

In terms of the embodied carbon; the concrete emits carbon more than steel in the manufacturing process.

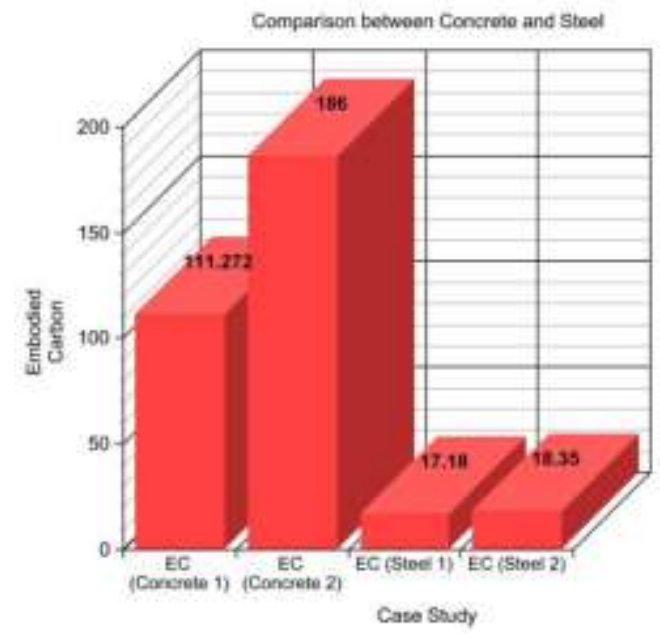

Figure 21: the difference between steel and concrete in embodied carbon.

To sum up, the manufacturing process of concrete consumes approximately double the energy that is used in the manufacturing process of steel. For steel; the ratio between the embodied energy and embodied carbon is constant. Thus, the concrete has more impact on the environment because of the carbon that is emitted through the manufacturing the concrete.
The concrete has adverse impact on the environment through the energy consumed in the manufacturing process. The steel consumes a small amount of energy through the manufacturing process and emits a small amount of carbon so it does not affect badly on the environment.

\section{Conclusion}

The paper explained an approach that helps in choosing the right material that has insignificant impact on the environment in terms of consumed energy and emitted carbon. That material called sustainable building material where that material can be maintained for a long time and reused by the next generations. The paper sums up the criteria to choose these materials as their waste production, energy consumption, Indoor environmental quality and emissions. Therefore, life cycle assessment (LCA) is used, that is a factual analysis of any products' entire life cycle in terms of sustainability. By using LCA any material can be evaluated to see its environmental impact from cradle to grave.

The embodied energy and embodied carbon have been used to know which material is efficient in the construction and manufacture process. The embodied energy calculates how much this material consume energy. And the embodied carbon calculates how much carbon

$\left(\mathrm{CO}_{2}\right)$ will be emitted from this material. The paper studied steel and concrete as they are the most used material in the construction in Egypt and compared between them in terms of embodied energy and embodied carbon. The analysis result shows that every meter square from steel consumes $323.23 \mathrm{MJ} / \mathrm{KG}$ and emitt17.765 $\mathrm{kgCO}_{2} \mathrm{e} / \mathrm{kg}$., while every meter square from concrete consume $1031.95 \mathrm{MJ} / \mathrm{KG}$ and emit $148.636 \mathrm{kgCO}_{2} \mathrm{e} / \mathrm{kg}$. The comparative analysis shows that the embodied energy of the concrete is approximately double the embodied energy of the steel. The embodied carbon of concrete is more than the embodied carbon of steel. Therefore, it is advisable to use steel as it is more sustainable and has better impact on the environment. 


\section{Recommendations:}

This study recommends build and design buildings more sustainable to live longer. To achieve that, the construction engineer and architecture should use the most sustainable way. In recent years, the construction industry increased and the effects that are produced by the emissions and impacts start to appear in the whole world and affect our daily life. Because of these effects, we should work on a way to save the environment. After making a study that proves that, the steel do not consume too much energy through the manufacturing process and emit less carbon than concrete. Therefore, the steel structure should spread worldwide to protect the environment from the greenhouse gases.

\section{References}

- Akadiri

P. and

Olomolaiye, P. (2012),

"Development of

sustainable assessment

criteria for building

materials selection",

Engineering, Construction

and Architectural

Management, Vol. 19 No.

6, pp. 666-687.

https://doi.org/10.1108/09

$\underline{699981211277568}$

- Berger, M. and Finkbeiner, M.

(2012) Methodological challenges in volumetric and impact-oriented water footprints. J. Ind. Ecol. doi:10.1111/j.15309290.2012.00495

- Ding, T., Jianzhuang Xiao, J., Tam, V., 'A closed-loop life cycle assessment of recycled aggregate concrete utilization in China', Waste Management

56, 2016, pp. 367-375.

- Gervasio, H. and Dimova, S. (2018). Model for Life Cycle Assessment (LCA) of buildings. Europ: Joint Research Centre. DOI: $10.2760 / 789069$

- $\quad$ Kuhlman, T. and Farrington, J. (2010) What is sustainability?

Sustainability, 2010 (2), 3436-3448. doi:10.3390/su2113436

- $\quad$ R, S. and Barkeley, L. (2014). Life cycle assessment (LCA) of woodbased building materials. Spain: Woodhead Publishing Online. DOI : 10.1533/9780857097729.2.311

- Rigamonti, L., Grosso, M., Modellizzazione dei prodotti evitati grazie ai materiali ottenuti dal riciclo, $3^{\circ}$ workshop "Rifiuti e Life Cycle Thinking" - Verso un utilizzo circolare delle risorse, Politecnico di Milano, 15 febbraio 2017.

- $\quad$ Singh, S. and Abdullah, S. (2019), "Durability analysis using Markov chain modeling under random loading for automobile crankshaft", International Journal of Structural Integrity, Vol. 10 No. 4, pp. 454468. https://doi.org/10.1108/IJSI03-2018-0016

- Suomala, P. (2005), "LIFE CYCLE PERSPECTIVE IN THE MEASUREMENT OF NEW PRODUCT DEVELOPMENT PERFORMANCE", Woodside, A. (Ed.) Managing Product Innovation (Advances in Business Marketing and Purchasing, Vol. 13), Emerald Group Publishing Limited, Bingley, 
pp. 523-700.

https://doi.org/10.1016/S10690964(04)13004-4

Tien, S., Chiu, C., Chung, Y., Tsai, C. and Chang, C. (2007), "Analysis of Production Process Improvement with Life Cycle Assessment Technology $\approx$ Example of HDPE

Pipe Manufacturing", Asian Journal on Quality, Vol. 8 No. 2, pp. 32-56. https://doi.org/10.1108/1598268820 $\underline{0700013}$ industries perspective using hybrid MCDM approaches", Journal of Advances in Management Research, Vol. 16 No. 2, pp. 234-259.

https://doi.org/10.1108/JAMR-09$\underline{2018-0085}$

- PACHECO-TORGAL, F. (2017). Eco-efficient construction and building materials. [London]: WOODHEAD.

- Mathiyazhagan, K., Gnanavelbabu, A. and Lokesh Prabhuraj, B. (2019), "A sustainable assessment model for material selection in construction 


\section{مدخل لاختيار المواد المستدامة باستخدام LCA}

الملخص:

مجال البناء هو واحد من أكبر المستفيدين من مصادر الطاقة المتجددة والغير متجددة في العالم. ولهذا كان من غير المكن تجنب ظهور الثكوك

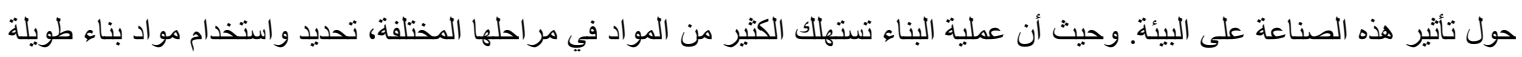

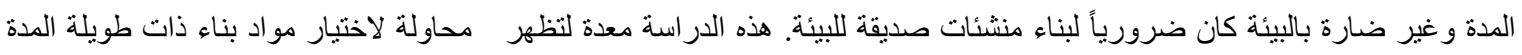

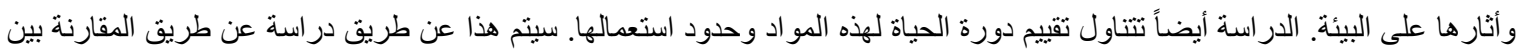

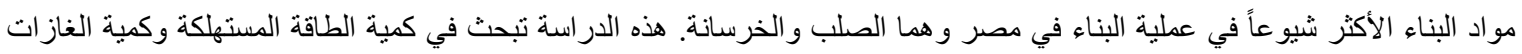

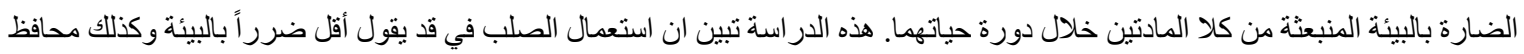
علي الطاقة المستخدمة في البناء. 